\title{
Hemodynamic Effects of the Combination of Dexmedetomidine-Fentanyl versus Midazolam-Fentanyl in Children Undergoing Cardiac Surgery with Cardiopulmonary Bypass
}

\author{
Jyrson Guilherme Klamt, TSA ${ }^{1}$, Walter Villela de Andrade Vicente ${ }^{2}$, Luis Vicente Garcia, TSA ${ }^{3}$, \\ César Augusto Ferreira ${ }^{4}$
}

Summary: Klamt JG, Vicente WVA, Garcia LV, Ferreira CA - Hemodynamic Effects of the Combination of Dexmedetomidine-Fentanyl versus Midazolam-Fentanyl in Children Undergoing Cardiac Surgery with Cardiopulmonary Bypass.

Background and objectives: To evaluate the efficacy of the combined infusion of dexmedetomidine and fentanyl on the hemodynamic response during cardiac surgery with cardiopulmonary bypass (CPB) in children.

\begin{abstract}
Methods: Thirty-two children, ages 1 month to 10 years, scheduled for cardiac surgery with cardiopulmonary bypass were randomly divided in two groups: the MDZ Group received midazolam $0.2 \mathrm{mg} \cdot \mathrm{kg}^{-1} \cdot \mathrm{h}^{-1}$, while the DEX group received dexmedetomidine $1 \mu \mathrm{gg} \cdot \mathrm{kg}^{-1} \cdot \mathrm{h}^{-1} \mathrm{during}$ one hour followed be a reduction by half in the rate of infusion in both groups. Both groups received fentanyl $10 \mu \mathrm{g} . \mathrm{kg}^{-1}$, midazolam $0.2 \mathrm{mg} \cdot \mathrm{h}^{-1}$, and vecuronium $0.2 \mathrm{mg} . \mathrm{kg}^{-1}$ for anesthesia induction. The same doses of fentanyl and vecuronium used during induction were infused during the first hour after induction, followed by a reduction to half. Infusions were initiated immediately after induction and maintained until the end of the surgery. Isoflurane was administered for a short time to control the hyperdynamic response to incision and sternotomy.
\end{abstract}

Results: In both groups, systolic blood pressure and heart rate reduced significantly after one hour of anesthetic infusion, but the increase in systolic and diastolic pressure and heart rate to skin incision were significantly lower in the DEX Group. A significantly lower number of patients demanded supplementation with isoflurane in the DEX Group. After CPB, patients in both groups had similar hemodynamic responses.

Conclusions: Infusion of dexmedetomidine without bolus seems to be an effective adjuvant to fentanyl on the promotion of sedation and control of hemodynamic responses during surgery for congenital cardiopathies in children.

Keywords: ANALGESIC, Opioids: fentanyl; DRUGS, Adrenergic agonist: dexmedetomidine; PRE-ANESTHETIC MEDICATION: midazolam; SURGERY, Cardiac: cardiopulmonary bypass.

\section{INTRODUCTION}

Midazolam (MDZ) is commonly used in association with fentanyl to promote hypnosis and deep anesthesia planes in surgeries for congenital cardiopathies. This combination guarantees adequate analgesia and amnesia and hemodynamic stability, even in children with low cardiac index ${ }^{1,2}$.

\footnotetext{
Received from the Hospital das Clinicas da Faculdade de Medicina de Ribeirão Preto, Universidade de São Paulo (FMRP-USP)

1. Assisting Professor; Department of Biomechanics, Medicine, and Rehabilitation of the Locomotor System of FMRP-USP

2. Professor; Department of Surgery and Anatomy of FMRP-USP; Chief of the Cardiotho2. Professor; Department of Surgery and
racic Surgery Department of FMRP-USP

3. Assisting Professor of FMRP-USP; Department of Biomechanics, Medicine, and Rehabilitation of the Locomotor System of FMRP-USP

4. Assisting Physician of the Hospital das Clínicas; Surgery and Anatomy Department of FMRP-USP

Submitted on January 21, 2010

Approved on March 15, 2010

Correspondence to:

Dr. Jyrson Guilherme Klamt

Serviço de Anestesia do Hospital das Clínicas da FMRP-USP

Av. Bandeirantes, 3900

Monte Alegre

14900-800 - Ribeirão Preto, SP

E-mail:jgklamt@fmrp.usp.br
}

Dexmedetomidine (DEX) is a highly specific and selective $\alpha_{2}$ adrenergic agonist with fast tissue distribution and short half-life, capable of producing postoperative sedation and analgesia controllable by continuous infusion ${ }^{3}$. Compare to MDZ, DEX as adjuvant in general anesthesia has superior sedative effects and similar hemodynamic and respiratory effects ${ }^{4}$. Dexmedetomidine promotes a reduction in the requirement of general anesthetics and opioids in different types of surgery ${ }^{3,5}$, and contrary to MDZ does not potentiate the depressor respiratory effects of opioids ${ }^{6}$. Additionally, it reduces the hyperdynamic responses (increased blood pressure and heart rate) mediated by the sympathetic nervous system ${ }^{5}$, and attenuate the cardiovascular and neuroendocrine response to surgery in pediatric patients during cardiac surgery with cardiopulmonary bypass (CPB) ${ }^{7}$. However, this last finding was observed in children with less than 1 year of age, with good general state and with less complex cardiopathies.

The objective of the present randomized and opened study was to compare the efficacy of continuous infusion of DEX and fentanyl versus MDZ and fentanyl on the hemodynamic response of children undergoing cardiac surgery with CPB. It was hypothesized that based on the capacity of DEX of potentiating the analgesia of opioids and reducing the sympathetic 
tonus, therefore reducing hemodynamic responses to surgical stress, it should be more effective than MDZ during anesthesia with fentanyl.

\section{METHODS}

After approval by the Ethics on Research Committee and signing of the informed consent by their parents, 32 consecutive pediatric patients ages between 0.7 to 108 months with congenital cardiopathies undergoing elective cardiac surgery with CPB were included in the present study.

Patients were randomly divided according to a computergenerated list (Excel-Microsoft) in two groups: continuous infusion of Fentanyl + MDZ (MDZ Group; $n=16$ ), or continuous infusion of fentanyl + DEX (DEX Group; $n=16$ ). The surgical and anesthesia teams were aware of the anesthetic regimen used for each patient. All preoperative infusions of vasoactive drugs, in case the patient was using them, were maintained until the onset of CPB. Anesthesia was induced with midazolam $\left(0.2 \mathrm{mg} \cdot \mathrm{kg}^{-1}\right)$, fentanyl $\left(10 \mu \mathrm{g} \cdot \mathrm{kg}^{-1}\right)$, and vecuronium (0.2 mg. $\left.\mathrm{kg}^{-1}\right)$. Non-invasive blood pressure was measured every two minutes until an artery was cannulated for continuous measurements, heart rate (HR) and pulse oximetry were monitored continuously. Baseline values were obtained after the administration of midazolam $\left(0.2 \mathrm{mg} \mathrm{kg}^{-1}\right)$ in the operating room. All patients received promethazine $\left(1 \mathrm{mg} \cdot \mathrm{kg}^{-1}\right)$ and ranitidine $\left(2 \mathrm{mg} \cdot \mathrm{kg}^{-1}\right)$.

After tracheal intubation and placement of temperature probes in the nasopharynx, in the lower third of the esophagus, and on the sole of the foot the ECG, PA, HR, $\mathrm{SpO}_{2}$, and $\mathrm{P}_{\mathrm{ET}} \mathrm{CO}_{2}$ were recorded and infusion of the anesthetic combination was instituted. The MDZ Group received infusion of fentanyl $\left(10 \mu \mathrm{g} \cdot \mathrm{kg}^{-1} \cdot \mathrm{h}^{-1}\right), \operatorname{MDZ}\left(0.2 \mathrm{mg} \cdot \mathrm{kg}^{-1} \cdot \mathrm{h}^{-1}\right)$, and vecuronium (0.2 mg. $\left.\mathrm{kg}^{-1} \cdot \mathrm{h}^{-1}\right)$ for one hour, and then those doses were reduced to half. In the DEX Group, DEX substituted MDZ, and it was used at a dose of $1 \mu \mathrm{g} \cdot \mathrm{kg}^{-2} \cdot \mathrm{h}^{-1}$ during one hour after which it was also reduced to half. The anesthetic agents in the infusion were mixed in the same syringe and the infusion was maintained until the end of the surgery before transporting the patient to the Pediatric Intensive Care Unit (PICU). Isoflurane (0.4-1.0\%) was used for a short period to maintain BP and $\mathrm{HR}$ at levels not higher than $20-30 \%$ of baseline levels during incision of the skin and sternotomy. The inspired concentration of oxygen $\left(\mathrm{FiO}_{2}\right)$ was maintained between 0.9-1.0, and $\mathrm{P}_{\mathrm{ET}} \mathrm{CO}_{2}$ between $35-45 \mathrm{mmHg}$. Positive end-expiratory pressure (PEEP) of 2-5 $\mathrm{cmH}_{2} \mathrm{O}$ and inspiration/expiration ratio (I/E) of 1/1.2-1.5 were used. During CPB the flow was of 2.5-3.0 L. $\mathrm{min}^{-1} \cdot \mathrm{m}^{-2}$, hematocrit was maintained between $25-30 \%$, pH was managed by the alpha-stat strategy, mean arterial pressure was maintained between $30-70 \mathrm{mmHg}$, and nasopharyngeal temperature was reduced to between $26^{\circ}$ to $32^{\circ} \mathrm{C}$ (at the surgeon's criteria).

Ringer's lactate was administered at a rate of $10 \mathrm{~mL} \cdot \mathrm{kg}^{-1} \cdot \mathrm{h}^{-1}$, and volumes $\left(5 \mathrm{~mL} . \mathrm{kg}^{-1}\right)$ were infused rapidly to maintain the CVP between 6-10 mmHg. After CPB, albumin 5\% and/ or blood from the cardiopulmonary pump were used to maintain the CVP between $12-16 \mathrm{mmHg}$. Glucose (100 mg. $\mathrm{kg}^{-1}$ ) was administered in case of hypoglycemia ( $\leq 70 \mathrm{mg} \cdot \mathrm{dL}$ ). Blood glucose was measured every 20-30 minutes. Central venous saturation $\left(\mathrm{SvO}_{2}\right)$ was used as an indicator of proper cardiac output and it was measured at least every 10-20 minutes or whenever necessary, and on the following moments: after the end of the first hour of the infusion of the anesthetic combination, before the onset of CPB, at the end of CPB, after administration of protamine, and at the end of the surgery. Once rewarming at the CPB was started, a bolus of milrinone $\left(50 \mu \mathrm{g} . \mathrm{kg}^{-1}\right)$ was administered followed by infusion of this drug $\left(0.5 \mu \mathrm{g} \cdot \mathrm{kg}^{-1}\right.$. $\left.\mathrm{min}^{-1}\right)$ in association with epinephrine $\left(0.02-0.2 \mu \mathrm{g} \cdot \mathrm{kg}^{-1} \cdot \mathrm{min}^{-1}\right)$. Hypotension was treated with ephedrine $\left(0.2 \mathrm{mg}^{\mathrm{kg}} \mathrm{k}^{-1}\right)$ or norepinephrine $\left(0.02-0.06 \mu \mathrm{g} \cdot \mathrm{kg}^{-1} \cdot \mathrm{min}^{-1}\right)$. Bradycardia without hypotension was treated with atropine $\left(30 \mu \mathrm{g} \cdot \mathrm{kg}^{-1}\right)$. Those vasoactive drugs were administered when the BP and HR were reduced below an expected level, with normal adjusted for the age ${ }^{8}$, or when they were reduced by $30 \%$ below baseline levels (after the initial administration of midazolam). Phenylephrine (1-5 $\left.\mu \mathrm{g} \cdot \mathrm{kg}^{-1}\right)$ was administered to treat hypotension and cyanosis in patients with tetralogy of Fallot. Tachycardia not associated with surgical stimulation was controlled with a bolus of esmolol (0.5-1.0 mg. $\left.\mathrm{kg}^{-1}\right)$. Sodium nitroprusside (NPS) (2-8 $\left.\mu \mathrm{g} \cdot \mathrm{kg}^{-1} \cdot \mathrm{min}^{-1}\right)$ was administered to control the BP during $\mathrm{CPB}$. Transitory reductions in $\mathrm{BP}$ secondary to surgical manipulation of the heart were not treated.

Preoperative cyanosis was defined as $\mathrm{SpO}_{2} \leq 90 \%$, rest or exercise-induced cyanosis (feedings in infants) observed or documented by the pediatrician. Preoperative heart failure was determined clinically by the pediatric cardiologist based on the echocardiogram or cardiac catheterization or treatment with digitalis and diuretics instituted at least one week before the surgery. Pulmonary hypertension $(\mathrm{PH})$ was determined by preoperative echocardiogram or cardiac catheterization. Crisis of $\mathrm{PH}$ after CPB was determined when the ratio between the pulmonary systolic pressure and systemic systolic blood pressure was greater than 0.5 . Intraoperative $\mathrm{PH}$ was monitored by a catheter in the pulmonary artery inserted by the surgeon via transatrial and transtricuspid before the end of CPB in patients with the diagnosis of preoperative $\mathrm{PH}$.

Hemodynamic parameters (BP, HR, temperature - nasopharyngeal, esophageal, and plantar) were recorded on the following moments: after sedation with MDZ (0.2 mg. $\left.\mathrm{kg}^{-1}\right)$ (Moment $M$, baseline levels), one hour after the onset of the infusion of the anesthetic combination $(1 \mathrm{H})$, before skin incision $(\mathrm{BI})$, immediately after skin incision (I), after sternotomy (S), 10 minutes after sternotomy (S10), three to five minutes after the administration of protamine $(P)$, and at the end of the surgery $(E)$. Skin incision was done after the first hour of the infusion. Blood pressure and $\mathrm{HR}$ were considered efficacy parameters in this study. Temperature, arterial blood gases, $\mathrm{SvO}_{2}$, and lactate levels were considered secondary parameters.

The Graph Pad Instat 3.0 and Graph Pad Prism4 (Graph Pad Software, San Diego, CA, USA) were used to estimate the size of the study population and for the statistical analysis, respectively. To determine the size of the study population BP data of previous studies $1,2,7$ were considered, and the findings of a pilot study as relevant clinical parameter. Calculation of the potency 
determined that 14 patients in each group would be enough for a $80 \%$ potency to detect a $20 \%$ difference in BP under a level of significance of $5 \%$. Friedman and Wilcoxon tests were used to analyze repeated measures of dependent parameters, the Mann-Whitney $U$ test to compare independent variables between both groups at each moment, while demographic parameters and the development of adverse events were analyzed by the Fisher test. The majority of the data is shown as mean $\pm \mathrm{SD}$. The level of significance was adjusted for $p<0.05$.

\section{RESULTS}

Thirty-seven patients were selected to participate in this study; five parents or guardians refused to have their children participate, while 32 approved and signed the informed consent. Two newborns in the MDZ Group were excluded: one due to excessive time (> 50 minutes) to insert the CVP or arterial catheter, and one because the surgery planned with CPB was changed for a systemic-pulmonary derivation without CPB. Two newborns in the DEX Group were also excluded from the analysis: one, a 3-day old baby with interruption of the aortic arch receiving $\mathrm{PGE}_{2}$, dopamine, and milrinone, required infusion of epinephrine for maintenance of the BP and HR, and the other, 18-day old, receiving $\mathrm{PGE}_{2}$, milrinone, and furosemide required norepinephrine also for maintenance of the BP before surgical manipulation. Infusion of DEX was continued until the end of the surgery on those two newborns. Table I shows patient characteristics, cardiac diagnosis, and duration of CPB and aortic clamping. A tendency for lower weight and age was observed in the DEX Group but this difference was not statistically significant. Preoperative cyanosis was significantly more frequent in the DEX Group, and more than $50 \%$ of the patients in both groups had a diagnosis of congestive heart failure. Preoperative $\mathrm{PH}$ was present in approximately $40 \%$ of the patients in both groups.
Levels of systolic blood pressure were lower, but not significant in the DEX Group in moment M (baseline). Heart rate and systolic pressure reduced significantly after one hour of infusion in both groups. In the MDZ Group, all hemodynamic variables increased significantly after incision of the skin (Moment I) in relation to before incision (Moment BI) (Figures 1, 2, and 3). Although a similar tendency was observed in the DEX Group it

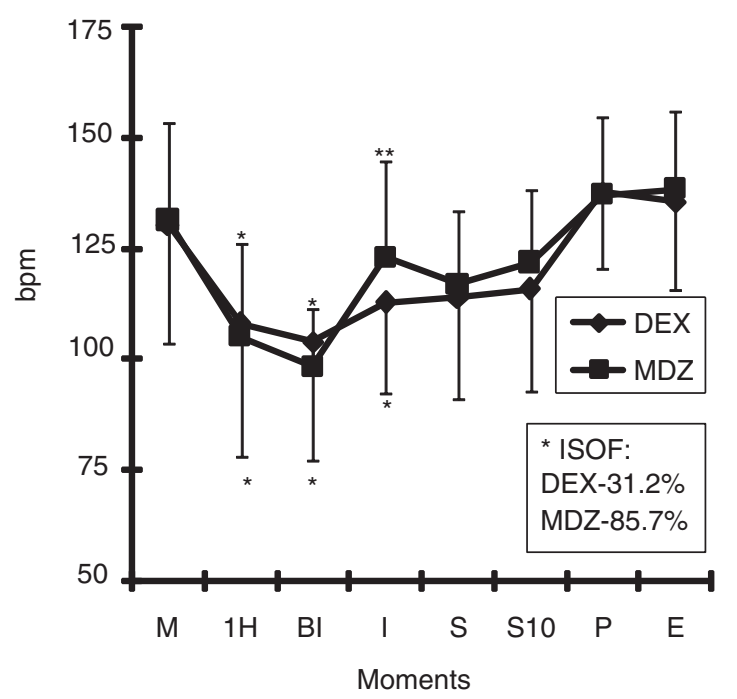

Figure 1. Effects of Dexmedetomidine (DEX) on Heart Rate (HR) during Cardiac Surgery with CPB in Children.

$\mathrm{M}$ - after midazolam (MDZ) $\left(0,2 \mathrm{mg}^{\mathrm{kg}}{ }^{-1}\right) ; 1 \mathrm{H}-$ after 1 hour of infusion of DEX $\left(1 \mu \mathrm{g} \cdot \mathrm{kg}^{-1}\right)$ or MDZ $\left(0,2 \mathrm{mg} \cdot \mathrm{kg}^{-1}\right)$ associated with fentanyl $\left(10 \mu \mathrm{g} . \mathrm{kg}^{-1}\right)$; $\mathrm{BI}$ - before skin incision; I - after skin incision; $\mathrm{S}$ - after sternotomy; S10 - 10 minutes after sternotomy; $\mathrm{P}$ - after administration of protamine; $\mathrm{E}-$ at the end of surgery. The box represents the percentage of patients who required isoflurane after skin incision.

Data represent Mean \pm SD.

*Significant difference in relation to $\mathrm{M}$, **in relation to $\mathrm{BI}$, and ${ }^{* * *}$ between groups.

Table I - Demographic Data, Diagnosis of Congenital Cardiopathies, Duration of CPB and Aortic Clamping, and Preoperative Incidence of Cyanosis, Heart Failure, and Pulmonary Hypertension

\begin{tabular}{lll}
\hline & Groups & \\
& MDZ $(\mathrm{n}=14)$ & $\mathrm{DEX}(\mathrm{n}=14)$ \\
\hline Age (months) - (variation) & $24.4 \pm 31.6(0.7-108)$ & $10.8 \pm 21.6(0.8-84)$ \\
Weight $(\mathrm{kg})$ & $10.2 \pm 16.1$ & $6.7 \pm 7.5$ \\
Gender (M / F) & $6 / 8$ & $8 / 6$ \\
CPB (min) & $101.9 \pm 41.5$ & $117.6 \pm 44.2$ \\
Aortic clamping (min) & $71.5 \pm 39.7$ & $76.1 \pm 26.7$ \\
Preoperative (\%) & & \\
$\quad$ & 28.6 & $56.3^{*}$ \\
$\quad$ Heanosis & 57.1 & 56.3 \\
$\quad$ Pulmonary hypertension & 42.8 & 37.5 \\
Congenital cardiopathies (n) & IAC (1); IAC+PDA (1); TAVSD+CIA (1); CIA+IVC & IAC (2); IAC+IVC (1); TAVSD (2); TAVSD+PDA \\
& $(1) ;$ TAVSD (1), DORV+CIA (2); IVC (2); PVS (1); & $(1) ;$ DORV (1); DORV+TGA (1); PVS (1); \\
& SubAo (1); TGA + IVC (1); TF (2) & TA+IAC (1); TA (1), TGA + PCD (1); TF (2) \\
\hline
\end{tabular}

Values expressed as Means $\pm \mathrm{SD}$, age variation, \%, or number of patients

${ }^{*}$ Statistically significant, $\mathrm{p}<0.05$

IAC = inter atrial communication; TAVSD = total atrioventricular septal defect; DORV = Double outlet right ventricle; IAAo = interruption of the aortic arch; PDA = persistent ductus arteriosus; PVS = pulmonary valve stenosis; SubAo = subaortic stenosis; TA = truncus arteriosus; TGA = transposition of great arteries; TF = Tetralogy of Fallot; IVC = interventricular communication. 


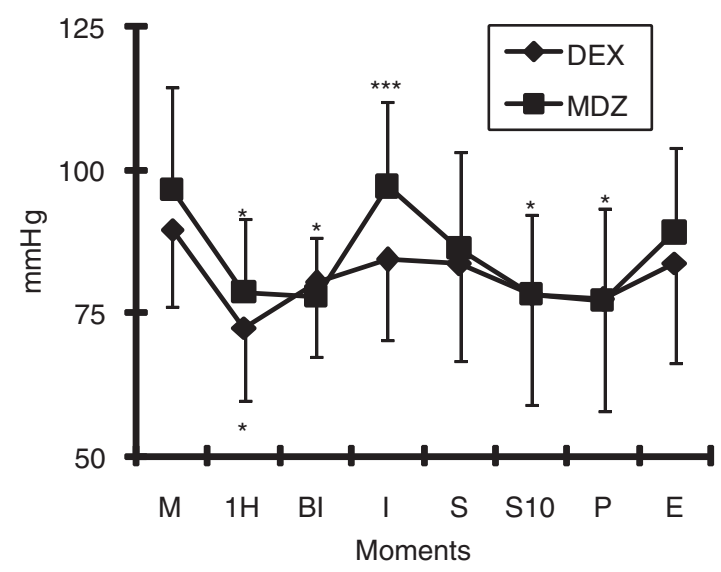

Figure 2. Effects of Dexmedetomidine (DEX) on Systolic Blood Pressure (SBP) during Cardiac Surgery with CPB on Children.

$\mathrm{M}$ - after midazolam (MDZ) $\left(0,2 \mathrm{mg}^{\mathrm{kg}}{ }^{-1}\right) ; 1 \mathrm{H}-1$ hour after infusion of DEX $\left(1 \mu \mathrm{g} \cdot \mathrm{kg}^{-1}\right)$ or MDZ $\left(0,2 \mathrm{mg} \cdot \mathrm{kg}^{-1}\right)$ associated with fentanyl $(10 \mu \mathrm{g}$. $\left.\mathrm{kg}^{-1}\right)$; $\mathrm{BI}$ - before skin incision; I - after skin incision; $\mathrm{S}$ - after sternotomy; S10 - 10 minutes after sternotomy; P - after administration of protamine; $\mathrm{E}-$ at the end of surgery.

Data represent Mean \pm SD.

*Significant difference in relation to $\mathrm{M}$, **in relation to $\mathrm{BI}$, and ***between groups.

was not statistically significant. More patients in the MDZ Group required supplementation with isoflurane (85.7\% versus $31.2 \%$, $p=0.027$ ). Cardiopulmonary bypass was associated with similar hemodynamic changes in both groups. The same was observed after administration of protamine (Moment $\mathrm{P}$ ), end of surgery (Moment E), and upon arrival to the Pediatric Intensive Care Unit. All patients showed BP, $\mathrm{HR}, \mathrm{SvO}_{2}$, and respiratory parameters considered adequate upon arrival to the PICU.

In the DEX Group one patient was on infusion of $\mathrm{PGE}_{2}$ and milrinone upon arrival to the operating room while another was on dopamine infusion. In the MDZ Group one patient was on $\mathrm{PGE}_{2}$ and milrinone infusion while another was on dobutamine infusion. Phenylephrine was administered to one patient in the MDZ Group and in two patients in the DEX Group. In the DEX Group, one patient received atropine before the onset of CPB while another required esmolol at the end of the surgery. The requirement of vasoactive support after CPB (epinephrine and norepinephrine infusion) was similar in both groups (Table II).

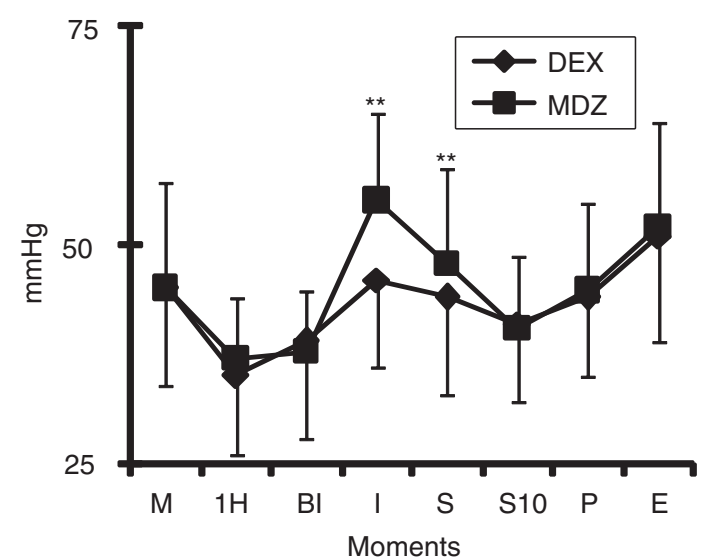

Figure 3. Effects of Dexmedetomidine (DEX) on Diastolic Blood Pressure (DBP) during Cardiac Surgery with CPB in Children.

$\mathrm{M}$ - after midazolam (MDZ) $\left(0,2 \mathrm{mg} \cdot \mathrm{kg}^{-1}\right) ; 1 \mathrm{H}-1$ hour after infusion of $\operatorname{DEX}\left(1 \mu \mathrm{g} \cdot \mathrm{kg}^{-1}\right)$ or MDZ $\left(0,2 \mathrm{mg}^{\mathrm{kg}} \mathrm{kg}^{-1}\right)$ associated with fentanyl $(10 \mu \mathrm{g}$. $\left.\mathrm{kg}^{-1}\right)$; $\mathrm{BI}$ - before skin incision; I - after skin incision; $\mathrm{S}$ - after sternotomy; S10 - 10 minutes after sternotomy; $\mathrm{P}$ - after administration of protamine; $\mathrm{E}-$ at the end of surgery.

Data represent Mean \pm SD.

*Significant difference in relation to $\mathrm{M}$, ${ }^{*}$ in relation to $\mathrm{BI}$, and ${ }^{* *}$ between groups.

Table III shows arterial and venous blood gases and glucose, lactate, hemoglobin, and platelet levels one hour after infusion of the anesthetic solution (Moment $1 \mathrm{H}$ ) and after administration of protamine (Moment $\mathrm{P}$ ). $\mathrm{PaO}_{2}$ increased after CPB, but only in the DEX Group it reached statistical significance (Table III).

Nasopharyngeal, esophageal, and plantar temperatures were similar in all moments in both groups. A two-year old in the DEX Group with nasopharyngeal temperature of $33^{\circ} \mathrm{C}$ and esophageal temperature of $36.5^{\circ} \mathrm{C}$ after $\mathrm{CPB}$ had prolonged sedation (absence of reaction to the tube and spontaneous respiration) during eight hours in the PICU without receiving infusion of sedative-analgesic drugs during this period. His neurological recovery was considered normal after this period. Patients who did not receive infusion of fentanyl and midazolam could be extubated between three and six hours in the PICU. One patient in the MDZ Group had hyperthermia $\left(39.5^{\circ} \mathrm{C}\right)$ and depression of the ST segment at the end of surgery, showing adequate response to dypirone $\left(20 \mathrm{mg}^{\mathrm{kg}}{ }^{-1}\right)$ and cooling of the skin.

Table II - Proportion of Patients and Rate of Infusion $\left(\mu \mathrm{g} \cdot \mathrm{kg}^{-1} \cdot \mathrm{min}^{-1}\right)$ (median and variation) of Vasoactive Drugs at the Time of Transfer to PICU (epinephrine and norepinephrine) and during CPB (sodium nitroprusside - NPS).

\begin{tabular}{llll}
\hline & Groups & & $*$ \\
\cline { 2 - 3 } & DEX & MDZ & - \\
\hline Milrinone & $14 / 14(0.8)$ & $14 / 14(0.8)$ & - \\
Epinephrine & $4 / 14(0.03) 0.03-0.05$ & $5 / 14(0.03) 0.03-0.05$ & - \\
Norepinephrine & $5 / 14(0.03) 0.03-0.05$ & $6 / 14(0.03) 0.03-0.05$ & - \\
NPS & $14 / 14(2)$ & $14 / 14(2)$ & \\
\hline
\end{tabular}

All patients received NPS $\left(2 \mu \mathrm{g} \cdot \mathrm{kg}^{-1} \cdot \mathrm{min}^{-1}\right)$ and milrinone $\left(50 \mu \mathrm{g} \cdot \mathrm{kg}^{-1}\right)$ during the rewarming phase of CPB

*Statistically different. 
KLAMT, VICENTE, GARCIA ET AL.

Table III - Blood Gases, Hemoglobin, and Platelet Concentration at the End of the First Hour of Infusion (1H) of Midazolam (MDZ) $\left(0.2 \mathrm{mg} \cdot \mathrm{kg}^{-1}\right)$ or Dexmedetomidine (DEX) $\left(1 \mu \mathrm{g} . \mathrm{kg}^{-1}\right)$ before Cardiopulmonary Bypass and Five minutes after the administration of protamine

\begin{tabular}{|c|c|c|c|c|}
\hline & \multicolumn{2}{|c|}{ 1st hour of infusion } & \multicolumn{2}{|l|}{ Protamine } \\
\hline & MDZ & DEX & MDZ & DEX \\
\hline$\overline{\mathrm{pH}}$ & $7.37 \pm 0.07$ & $7.38 \pm 0.1$ & $7.33 \pm 0.05$ & $7.36 \pm 0.09$ \\
\hline $\mathrm{PaO}_{2}(\mathrm{mmHg})$ & $188.1 \pm 133.2$ & $121.3 \pm 85.9$ & $247.5 \pm 157.2$ & $298.3 \pm 150$ * \\
\hline $\mathrm{PaCO}_{2}(\mathrm{mmHg})$ & $35.2 \pm 4.0$ & $41.3 \pm 12.2$ & $41.9 \pm 7.6$ & $37.7 \pm 9.5$ \\
\hline $\mathrm{HCO}_{3}^{-}\left(\mathrm{mmol} . \mathrm{L}^{-1}\right)$ & $23.1 \pm 3.9$ & $24.1 \pm 5.6$ & $21.9 \pm 2.5$ & $20.9 \pm 2.8$ \\
\hline $\mathrm{BE}$ & $0.6 \pm 4.4$ & $-0.9 \pm 5.9$ & $-3.6 \pm 2.3$ & $-3.6 \pm 3.5$ \\
\hline Glucose (mg.100 mL-1) & $81.9 \pm 16.8$ & $113.2 \pm 66.1$ & $193.3 \pm 49.7$ & $180.1 \pm 43.9$ \\
\hline Lactate $\left(\mathrm{mmol} . \mathrm{L}^{-1}\right)$ & $1.1 \pm 0.4$ & $1.5 \pm 0.5$ & $2.9 \pm 0.7$ & $3.8 \pm 1.9$ \\
\hline $\mathrm{Na}^{+}\left(\mathrm{mmEq} \cdot \mathrm{L}^{-1}\right)$ & $134.2 \pm 4.4$ & $132 \pm 3.1$ & $139.7 \pm 4.6$ & $140.4 \pm 3.9$ \\
\hline $\mathrm{K}^{+}\left(\mathrm{mmEq} \cdot \mathrm{L}^{-1}\right)$ & $4.1 \pm 0.4$ & $4.1 \pm 0.6$ & $3.6 \pm 0.3$ & $3.7 \pm 0.4$ \\
\hline $\mathrm{Ca}^{++}\left(\mathrm{mmEq} \cdot \mathrm{L}^{-1}\right)$ & $1.2 \pm 0.1$ & $1.2 \pm 0.1$ & $1.3 \pm 0.1$ & $1.2 \pm 0.1$ \\
\hline
\end{tabular}

Data represent Mean \pm SD

${ }^{*} \mathrm{FiO}_{2}=1.0$; ${ }^{*}$ Significant difference in relation to $1 \mathrm{H}$.

\section{DISCUSSION}

The present study was undertaken to evaluate the anesthetic effectivity and safety of the combination of fentanyl and DEX when compared with the routine technique for children undergoing cardiac surgery with $\mathrm{CPB}$, which is based on the infusion of fentanyl and DMZ supplemented with isoflurane. Both anesthetic regimens promoted effective anesthesia and they could be easily complemented with isoflurane to control hyperdynamic responses. The increase in BP and HR to skin incision was more easily controlled in the DEX Group and less patients required isoflurane in this group. The open label design of this study was recommended because both drugs (DEX and MDZ) have distinctive pharmacologic profiles and their respective adverse effects require different managing strategies. Both groups had similar demographic characteristics, except for a tendency to lower weight and age, as well as higher incidence of cyanotic cardiopathy in the DEX Group. Systolic blood pressure also showed a tendency to be smaller in the DEX Group. Patients in both groups showed comparable hemodynamic parameters, arterial blood gases, $\mathrm{SvO}_{2}$, and lactate levels at the end of the surgery.

The protocol based on fentanyl and midazolam plus isoflurane was adapted to our population of pediatric patients including newborns in especial those with low cardiac index based on the demonstration of its effectivity and safety to promote analgesia and hypnosis while preserving hemodynamic stability in children undergoing cardiac surgery ${ }^{2,9,10}$. The dose of DEX has been more investigated for non-painful procedures such as MRI ${ }^{4,11,12}$, cardiac catheterization ${ }^{13,14}$, or bronchoscopy ${ }^{15}$. Few studies have focused on regimen of doses for children with congenital cardiopathy. The study of Mukhtar et al. ${ }^{7}$ used in children older than 1 year and with less complex cardiopathies similar doses to those recommended for normal adults (bolus of $0.5 \mu \mathrm{g} \cdot \mathrm{kg}^{-1}$, followed by $0.5 \mu \mathrm{g} \cdot \mathrm{kg}^{-1} \cdot \mathrm{h}^{-1}$ ) which proved to be effective in attenuating the hemodynamic and neuroendocrine response to surgery without any deleterious hemodynamic effects. On the other hand, Hammer et al. ${ }^{16}$ demonstrated on a electrophysiological study that this dose suppresses the rhythm of the sinus node and function of the AV node in children. Commonly, DEX is administered in bolus $\left(0.5-1.0 \mu \mathrm{g}^{\mathrm{kg}}{ }^{-1}\right)$ followed by infusion at a rate of 0.2 to $2.0 \mu \mathrm{g}$. $\left.\mathrm{kg}^{-1} \cdot \mathrm{h}^{-1}\right)$. The attack dose can cause severe hypotension, bradycardia, or even sinus arrest when injected rapidly especially in small children with cardiac diseases on medication capable of producing negative chronotropic effects (beta-adrenergic antagonists and digoxin) or reduced volemia ${ }^{17,18}$. Since the majority of patients in the present study had those characteristics the attack dose was omitted to avoid fast hemodynamic changes. Dexmedetomidine infusion $\left(1 \mu \mathrm{g} \cdot \mathrm{kg}^{-1} \cdot \mathrm{h}^{-1}\right)$, which was initiated soon after anesthetic induction, should not have compromised sedation since it presumably substituted the sedative and hypnotic effects of midazolam $\left(0.2 \mathrm{mg} \mathrm{kg}^{-1}\right)$. This gradual substitution of MDZ by DEX is frequently used in intensive care units. It has been demonstrated that the rate of infusion of $0.5 \mu \mathrm{g} \cdot \mathrm{kg}^{-1} \cdot \mathrm{h}^{-1}$ is highly effective in promoting sedation and analgesia for mechanical ventilation even without prior bolus ${ }^{21}$.

The efficacy of the parameters of the present study were: the hemodynamic effects (BP and HR) and the control of hemodynamic responses to surgical stress of the infusion of fentanyl plus DEX when compared to our routine technique (fentanyl and MDZ). In both groups, HR and systolic blood pressure reduced significantly during the period of one hour before the 
onset of surgical stimulation. However, the hyperdynamic response to skin incision was significant only in the MDZ group whose patients also demanded greater supplementation of isoflurane. The potentiation of opioid analgesia observed is in agreement with the well-known opioid-sparing effect of DEX 3. After CPB, the hemodynamic profile and vasoactive support were similar in both anesthetic regimens. However, two patients in the DEX Group who were on $\mathrm{PGE}_{2}$ and milrinone upon arrival to the operating room developed hypotension and bradycardia in levels below accepted and were treated with norepinephrine. They continued on DEX, but they were excluded from the statistical analysis. The results presented in this study are also consistent with studies that showed that DEX promotes effective sedation and analgesia with hemodynamic stability and inhibits responses mediated by the sympathetic system during critical moments of the surgery, such as skin incision and sternotomy, even though it can produce fatal hypotension and bradycardia and require immediate vasoactive support $3,7,22$.

Fentanyl has a fast onset of action and it causes minimal hemodynamic changes, even when high doses are administered to pediatric patients with very low cardiac index. However, when administered in combination with benzodiazepines it can provoke circulatory depression and require volemic expansion, and in some cases inotropic support 1,2,9,19. Revines et al. ${ }^{1}$ demonstrated that the combination of fentanyl and midazolam depresses the HR, BP, and cardiac index despite unchanged cardiac contractility. In the present study it was not possible to verify whether the combination of fentanyl and DEX compromised the cardiac output to the same extent of the combination of fentanyl and midazolam, despite the presence of similar $\mathrm{SvO}_{2}$ at the recording moments. However, it is known that DEX at an infusion rate greater than $0.5 \mu \mathrm{g}$. $\mathrm{kg}^{-1} \cdot \mathrm{min}^{-1}$ can reduce the cardiac output ${ }^{23}$. However, DEX has been used in total intravenous anesthesia in doses as high as $10 \mu \mathrm{g} \cdot \mathrm{kg}^{-1} \cdot \mathrm{h}^{-1}$ without inducing severe hypotension or bradycardia ${ }^{15,24}$. Recently, Mason et al. ${ }^{12}$ reported that elevated doses of DEX (2-3 $\left.\mu \mathrm{g}^{\mathrm{kg}} \mathrm{kg}^{-1}\right)$ over 10 minutes and infusion of 1.5$3.0 \mu \mathrm{g} \cdot \mathrm{kg}^{-1} \cdot \mathrm{h}^{-1}$ in children undergoing MRI produce bradycardia in approximately $16 \%$ of those patients, but mean arterial pressure and arterial oxygen saturation remain within normal limits. They did not observe sequelae and specific treatment was not necessary, but children with cardiopathies were not included in their study and opioids were not administered. Until now, this study is the first one to report the combined use of anesthetic doses of fentanyl with effective sedative dose of DEX in children including newborns during cardiac surgery with CPB. The study of Mukhtar et al. ${ }^{7}$ involves children of over 1 year of age with less complex cardiopathies (possibly with a cardiac index with little compromise) and uses lower doses of fentanyl. The two anesthetic regimens evaluated in the present study revealed hemodynamic efficacy after CPB. Indeed, all children arrived at the PICU with hemodynamic parameters, respiratory function, $\mathrm{SvO}_{2}$, and lactate levels qualified as adequate or expected. Currently, as recommended by Easley and Tobias ${ }^{22}$, in children older than 1 year of age not receiving vasoactive support, we initiated DEX shortly after anesthetic induction, and in younger children only after introducing central venous and arterial lines.

The potential for hypotension and systemic vasodilation due to the sympatholytic actions of DEX should be seriously considered in children with cyanotic cardiopathy since it can increase the right-to-left shunt and worsen hypoxemia. Despite having more children with cyanotic cardiopathies in the DEX Group, differences in pulse oximetry in relation to the MDZ Group were not observed possibly because the elevated $\mathrm{FiO}_{2}$ and fentanyl contrapose this harmful effect. On the other hand, the greater proportion if cyanotic cardiopathies may explain the significant increase of $\mathrm{PaO}_{2}$ after $\mathrm{CPB}$ in this group. One should be more careful in patients with a fixed cardiac output, such as in severe aortic stenosis, since the vasodilation can reduce cerebral and coronary perfusion 25 . It was expected that patients in the DEX Group would need less sodium nitroprusside and higher cutaneous temperature due to the vasodilation produced by DEX; however, this effect was not observed. Due to the little experience with DEX in critical pediatric patients or pediatric patients undergoing cardiac surgery, until now publications on the effects of DEX on the balance between pulmonary and systemic vascular resistance in the physiology of a single ventricle are not available. We excluded children undergoing Norwood, Glenn, and Fontan surgeries.

In healthy volunteers DEX generates a dose-dependent increase in pulmonary vascular resistance (PVR) and pulmonary arterial pressure (PAP), and in animal models the fast administration of high doses of DEX increases transitorily PVR and PAP ${ }^{3,22}$. Those effects are not reported in adults or in children undergoing cardiac surgeries with CPB and in diagnostic cardiac catheterization, and the few episodes of $\mathrm{PH}$ after CPB seem both in the DEX and MDZ groups were easily controlled. The episode of low nasopharyngeal temperature after CPB seem in one patient in the DEX Group could result from cerebral vasoconstriction related with the administration of DEX. Dexmedetomidine reduces cerebral blood flow secondary to the reduction of cerebral perfusion pressure, but without deleterious effects in cerebral oxygenation even in the presence of hyperventilation, and it can even have a neuroprotective effect in situations with risk of ischemia and hypoxia followed by neuronal damage, which are common in cardiac surgeries ${ }^{3,22,26}$.

To conclude, the association of a continuous infusion of DEX without a bolus with fentanyl promotes effective anesthesia in pediatric patients undergoing cardiac surgery with CPB when compared with the group who received classical routine anesthesia with fentanyl and MDZ. Additionally, the hyperdynamic responses to surgical stimulus were better controlled with DEX. Note that hypotensive response that demands immediate treatment can develop, and, therefore, the availability of vasoactive drugs ready to be used is mandatory. Thus, the selection of the dose of DEX should be careful or even avoided in hemodynamically compromised patients. 


\section{REFERÊNCIAS / REFERENCES}

01. Rivenes SM, Lewin MB, Stayer SA et al. - Cardiovascular effects of sevoflurane, isoflurane, halothane, and fentanyl-midazolan in children with congenital heart disease: an echocardiographic study of myocardial contractility and hemodynamics. Anesthesiology 2001;94:223-229.

02. Gruber EM, Laussen PC, Costa A et al. - Stress response in infants undergoing cardiac surgery: a randomized study of fentanyl bolus, fentanyl infusion, and fentanyl-midazolam infusion. Anesth Analg, 2001;92:882-890.

03. Gerlach AT, Dasta JF - Dexmedetomidine: an update review. Ann Pharmacother, 2007;41:245-252.

04. Koroglu A, Demirbilek S, Teksan H et al. - Sedative, haemodynamic and respiratory effects of dexmedetomidine in children undergoing magnetic resonance imaging examination: preliminary results. $\mathrm{Br} \mathrm{J}$ Anaesth, 2005;94:821-824.

05. McCutcheon CA, Orme RM, Scott DA et al. A comparison of dexmedetomidine versus conventional therapy for sedation and hemodynamic control during carotid endarterectomy performed under regional anesthesia. Anesth Analg, 2006;102:668-675.

06. Arain SR, Ruehlow RM, Uhrich TD et al. - The efficacy of dexmedetomidine versus morphine for postoperative analgesia after major inpatient surgery. Anesth Analg 2004;98:153-158.

07. Mukhtar AM, Obayah EM, Hassona AM - The use of dexmedetomidine in pediatric cardiac surgery. Anesth Analg, 2006;103:52-56.

08. Lerman J, Sikich N, Kleinman S et al. - The pharmacology of sevoflurane in infants and children. Anesthesiology, 1994;80:814-824.

09. Pirat A, Akpek E, Arslan G - Intrathecal versus IV fentanyl in pediatric cardiac anesthesia. Anesth Analg 2002;95:1207-1214.

10. Laird TH, Stayer SA, Rivenes SM et al. - Pulmonary-to-systemic blood flow ratio effects of sevoflurane, isoflurane, halothane and fentanyl/midazolam with $100 \%$ oxygen in children with congenital heart disease. Anesth Analg, 2002;95:1200-1206.

11. Koroglu A, Teksan H, Sagir $\mathrm{O}$ et al. - A comparison of the sedative, hemodynamic, and respiratory effects of dexmedetomidine and propofol in children undergoing magnetic resonance imaging. Anesth Analg, 2006;103:63-67.

12. Mason KP, Zurakowski D, Zgleszewski SE et al. - High dose dexmedetomidine as the sole sedative for pediatric MRI. Pediatr Anesth 2008;18:403-11.

13. Tosun Z, Akin A, Guler G et al. - Dexmedetomidine-ketamine and propofol-ketamine combinations for anesthesia in spontaneously breathing pediatric patients undergoing cardiac catheterization. J Cardiothorac Vasc Anesth, 2006;20:515-519.

14. Munro HM, Tirotta CF, Felix DE et al. - Initial experience with dexmedetomidine for diagnostic and interventional cardiac catheterization in children. Pediatr Anesth, 2007;17:109-112.

15. Shukry M, Kennedy $\mathrm{K}$ - Dexmedetomidine as a total intravenous anesthetic in infants. Pediatr Anesth 2007;17:581-583.

16. Hammer GB, Drover DR, Cao $\mathrm{H}$ et al. - The effects of dexmedetomidine on cardiac electrophysiology in children. Anesth Analg, 2008; 106:79-83.

17. Deutsch E, Tobias JD - Hemodynamic and respiratory changes following dexmedetomidine administration during general anesthesia: sevofluorane vs. desfluorane. Pediatr Anesth 2007;17:438-444.

18. Berkenbosh JW, Tobias JD - Development of bradycardia during sedation with dexmedetomidine in an infant concurrently receiving digoxin. Pediatr Crit Care Med, 2003;4:203-205.

19. Ickeringill $M$ Shehabi $Y$, Adamson $\mathrm{H}$ et al. - Dexmedetomidine infusion without loading dose in surgical patients requiring mechanical ventilation: haemodynamic effects and efficacy. Anaesth Intensive Care 2004;32:741-745

20. Hammer GB, Philip BM, Schroeder AR et al. - Prolonged infusion of dexmedetomidine for sedation following tracheal resection. Pediatr Anesth 2005;15:616-620.

21. Tobias JD, Berkenbosh JW - Sedation during mechanical ventilation in infants and children: dexmedetomidine versus midazolam. South Med J 2004;97:451-465.

22. Easley RB, Tobias JD - Pro: dexmedetomidine should be used for infants and children undergoing cardiac surgery. J Cardiothorac Vasc Anesth, 2008;22:147-151.

23. Ozkose Z, Dermir FS, Pambal K et al. - Hemodynamic and anesthetic advantages of dexmedetomidine an alpha 2-agonist, for surgery in prone position. Tahoku J Exp Med, 2006;210:153-160.
24. Ramsay MA, Luterman DC - Dexmedetomidine as a total intravenous anesthetic agent. Anesthesiology 2004;101:787-790.

25. Rosen DA, Rosen KR - Anomalies of the Aortic Arch and Valve, em: Lake CL, Brooker PD - Pediatric Cardiac Anesthesia. $4^{\text {th }}$ Ed, Philadelphia, Lippincott Williams \& Wilkins, 2005;381-424.

26. Janke EL, Samra S - Dexmedetomidine and neuroprotection. Semin Anesth Perioper Med Pain, 2006;25:71-76.

Resumen: Klamt JG, Vicente WVA, Garcia LV, Ferreira CA - Efectos Hemodinámicos de la Combinación de Dexmedetomidina-Fentanil versus Midazolam-Fentanil en Ninõs Sometidos a la Cirugía Cardíaca con Circulación Extracorpórea.

Justificativa y objetivos: Evaluar la eficacia de la infusión combinada de dexmedetomidina y fentanil en la respuesta hedominámica durante la cirugía cardíaca con circulación extracorpórea (CEC) en niños.

Método: Treinta y dos niños, con edad entre 1 mes y 10 años, citados para cirugía cardíaca con circulación extracorpórea, que fueron distribuidos aleatoriamente en dos grupos: el Grupo MDZ recibió midazolam $0,2 \mathrm{mg} \cdot \mathrm{kg}^{-1} \cdot \mathrm{h}^{-1}$, mientras que el Grupo DEX recibió dexmedetomidina $1 \mu \mathrm{g} \cdot \mathrm{kg}^{-1} \cdot \mathrm{h}^{-1}$ durante una hora y enseguida el ritmo de infusión se redujo a la mitad en los dos grupos. Los dos grupos recibieron fentanil $10 \mu \mathrm{g}$. $\mathrm{kg}^{-1}$, midazolam $0,2 \mathrm{mg} \cdot \mathrm{h}^{-1}$ y vecuronio $0,2 \mathrm{mg} \cdot \mathrm{kg}^{-1}$ para la inducción de la anestesia. Las mismas dosis de fentanil con vecuronio de la inducción fueron infundidas durante la primera hora después de la inducción y enseguida reducidas a la mitad. Las infusiones fueron iniciadas inmediatamente después de la inducción y mantenidas hasta el final de la cirugía. El isoflurano se administró por un corto tiempo para el control de la respuesta hiperdinámica a la incisión y esternotomía.

Resultados: En los dos grupos, la presión arterial sistólica y la frecuencia cardíaca se redujeron ostensiblemente después de una hora de infusión anestésica, pero el aumento de la presión arterial sistólica y diastólica y el de la frecuencia cardíaca al momento de la incisión de la piel, fueron significantemente menores en el Grupo DEX. Un número significativamente menor de pacientes exigió un suplemento con isoflurano en el Grupo DEX. Después de la CEC, los pacientes de los dos grupos tuvieron respuestas hedominámicas similares.

Conclusiones: La infusión sin bolo de dexmedetomidina parece ser un adyuvante efectivo del fentanil en la promoción de la sedación y el control de las respuestas hemodinámicas durante la cirugía para las cardiopatías congénitas en niños. 